\section{Spontaneous Rupture of a Biliary Metal Stent}

Endoscopic drainage using endoprostheses is an established method of palliation for inoperable pancreatic cancer. Metal stents have been shown to have a significantly better patency rate than plastic prostheses for this purpose $(1,2)$. We describe here an unusual complication of metal stent placement in a 58-year-old man with surgically proved unresectable cancer of the pancreatic head (peritoneal carcinomatosis).

Rapid occlusion of the plastic prosthesis that was initially placed led to the implantation of an 8-cm uncovered nitinol metal stent (Diamond stent, Boston Scientific/ Microvasive). The duodenal end of the stent was positioned $5-6 \mathrm{~mm}$ below the level of the papilla to prevent overgrowth. Six weeks later, however, the patient presented again with fever and elevated laboratory values, indicating cholestasis. Fluoroscopy before endoscopic retrograde cholangiopancreatography (ERCP) already indicated that the distal third of the stent had become disconnected, with widening of the mesh in this part (Figure 1). Due to duodenal stricturing at the level of the papilla, it was only possible to carry out ERCP with an II-mm duodenoscope. During intubation of the common bile duct, the distal part of the stent was mobilized (Figure 2), and it was then easily extracted and removed using a forceps (Figure 3). The remaining part of the stent, which was occluded, was bridged by inserting two 7-Fr plastic prostheses. The patient's symptoms then improved.

Possible reasons for breakage in this stent might be defects in the material, or shearing forces; it could be speculated that such forces acted on the 5-6 $\mathrm{mm}$ distal end of the stent in the duodenum. In an earlier case, breakage of a metal stent (Wallstent) was reported when a percutaneous drainage tube was inserted through the stent (3). but similar external forces were not applied in this case. In the present patient, the common bile duct was still easily cannulated. The percutaneous drainage which became necessary several weeks later, after the duodenal stricture restricted further endoscopic manipulations (4), was probably made easier due to the fact that the distal end of the metal stent did not extend into the descending duodenum.

P. Born. T. Rösch, M. Classen

Dept. of Internal Medicine II, Technical University of Munich, Munich, Germany

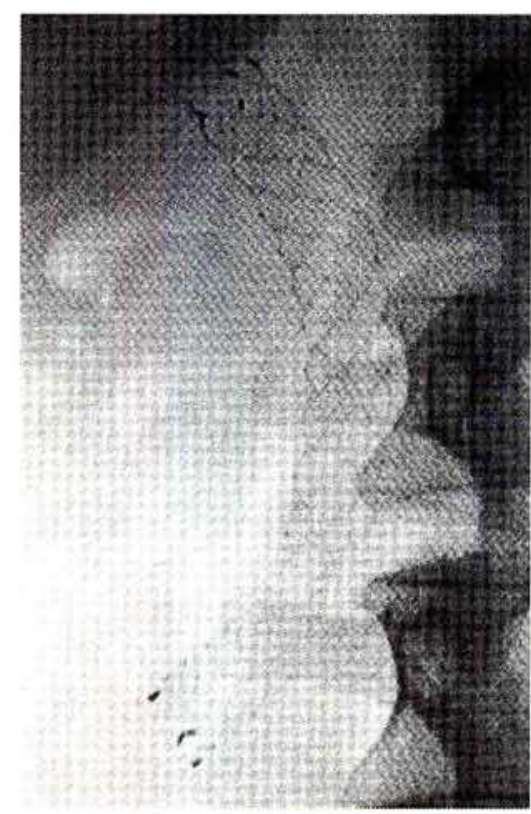

Figure 1: Fluoroscopy before the ERCP, already showing the break in the stent.

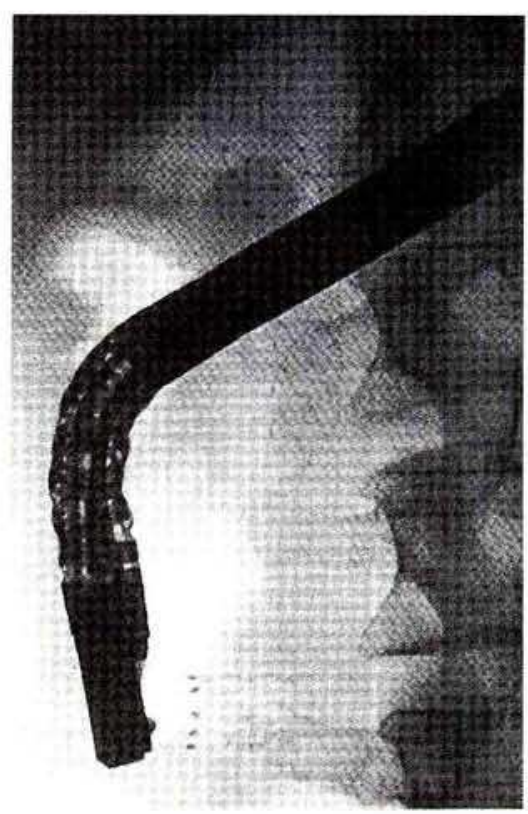

Figure 2: Mobilizing the distal part of the stent during cannulation of the bile duct

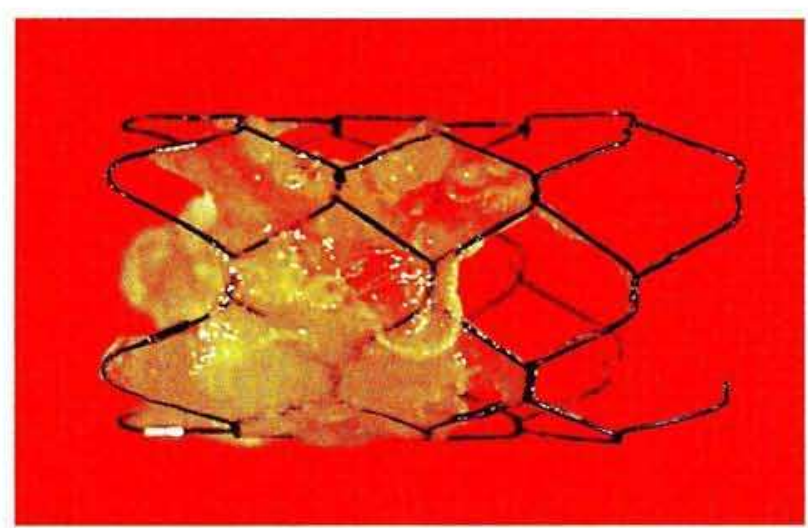

Figure 3: The extracted broken section of the stent.

\section{References}

1. Knyrim K, Wagner HJ, Pausch J, Vakil N. A prospective randomized, controlled trial of metal stents for malignant obstruction of the common bile duct. Endoscopy 1993; 25:207-12.

2. Gottlieb K, Sherman S, Lehman GA. Therapeutic biliary endoscopy. Endoscopy 1996; 28: 113-30.

3. Born P, Rösch T, Classen M. Breakage of an endobiliary metal stent. Endoscopy 1996; $28: 526$.
4. Born P, Neuhaus H, Rösch T, et al. A minimally invasive palliative approach to advanced pancreatic and papillary cancer causing both biliary and duodenal obstruction. Z Gastroenterol 1996; 34: 416-20.

Corresponding Author P. Born, M.D.

II. Medizinische Klinik Klinikum Rechts der Isar Technische Universität München Ismaningerstrasse 22 81675 München, Germany Fax: + 49-89-4l40-4905 